\title{
Position paper: management of perforated sigmoid diverticulitis
}

\author{
Frederick A Moore $^{1 *}$, Fausto Catena ${ }^{2}$, Ernest E Moore ${ }^{3}$, Ari Leppaniemi ${ }^{4}$ and Andrew B Peitzmann ${ }^{5}$
}

\begin{abstract}
Over the last three decades, emergency surgery for perforated sigmoid diverticulitis has evolved dramatically but remains controversial. Diverticulitis is categorized as uncomplicated (amenable to outpatient treatment) versus complicated (requiring hospitalization). Patients with complicated diverticulitis undergo computerized tomography (CT) scanning and the CT findings are used categorize the severity of disease. Treatment of stage I (phlegmon with or without small abscess) and stage II (phlegmon with large abscess) diverticulitis (which includes bowel rest, intravenous antibiotics and percutaneous drainage ( $P C D)$ of the larger abscesses) has not changed much over last two decades. On the other hand, treatment of stage III (purulent peritonitis) and stage IV (feculent peritonitis) diverticulitis has evolved dramatically and remains morbid. In the 1980s a two stage procedure $\left(1^{\text {st }}\right.$ - segmental sigmoid resection with end colostomy and $2^{\text {nd }}$ - colostomy closure after three to six months) was standard of care for most general surgeons. However, it was recognized that half of these patients never had their colostomy reversed and that colostomy closure was a morbid procedure. As a result starting in the 1990s colorectal surgical specialists increasing performed a one stage primary resection anastomosis (PRA) and demonstrated similar outcomes to the two stage procedure. In the mid 2000s, the colorectal surgeons promoted this as standard of care. But unfortunately despite advances in perioperative care and their excellent surgical skills, PRA for stage III/IV diverticulitis continued to have a high mortality (10-15\%). The survivors require prolonged hospital stays and often do not fully recover. Recent case series indicate that a substantial portion of the patients who previously were subjected to emergency sigmoid colectomy can be successfully treated with less invasive nonoperative management with salvage $P C D$ and/or laparoscopic lavage and drainage. These patients experience a surprisingly lower mortality and more rapid recovery. They are also spared the need for a colostomy and do not appear to benefit from a delayed elective sigmoid colectomy. While we await the final results ongoing prospective randomized clinical trials testing these less invasive alternatives, we have proposed (based primarily on case series and our expert opinions) what we believe safe and rationale management strategy.
\end{abstract}

Keywords: Complicated diverticulitis, Hartmann's procedure, Primary resection anastomosis, Laparoscopic lavage and drainage, Percutaneous drainage

\section{Introduction}

This position paper updates the literature related to the management of perforated sigmoid diverticulitis with the goals of identifying a) key management decisions, b) alternative management options and c) gaps in our knowledge base that can be targeted in a future emergency surgery research agenda $[1,2]$. From this we have created a decision making algorithm that can be modified based

\footnotetext{
* Correspondence: Frederick.Moore@surgery.ufl.edu

${ }^{1}$ Acute Care Surgery, University of Florida, 1600 Southwest Archer Road, PO Box 100108, Gainesville, FL 32610-0108, USA

Full list of author information is available at the end of the article
}

on evolving evidence and local resources to guide institutional practices. This manuscript will provide the basis for a future evidence based guideline (EBG) that will be developed and endorsed by the World Society of Emergency Surgery and published in the World Journal of Emergency Surgery. We envision that the EBG recommendations will be graded based on the level of evidence and will identify the resources needed to provide optimal care. Recognizing the tremendous variability in hospital resources available worldwide, this optimal resource information will be used to designate levels of acute care surgery hospitals (similar to trauma centers). This designation 
process will be used to leverage hospitals to upgrade their resources to optimize their emergency surgery capabilities.

\section{Background and significance Pathogenesis}

Diverticular disease is common affecting over $50 \%$ of men and women older than 65 years. Diverticulitis is inflammation of the colon that occurs as a result of perforation of a diverticulum almost exclusively in the sigmoid colon and incidence is estimated to be 3.4 to 4.5 per 100,000 people per year [3-6]. Diverticulitis is known as the disease of the industrial revolution, since there are no reports or pathologic specimens documenting evidence of diverticular disease prior to the 1900s [7]. In the late 1800s, the process of roller-milling wheat was introduced which removes two thirds of the fiber content of wheat. Coincident with this implementation, diverticulosis was observed in the first decade of the 1900s. It is now known that a diet low in fiber is a contributing factor in the development of diverticular disease [7-9]. In a study of nearly 48,000 US men, a low-fiber diet increased the risk of symptomatic diverticular disease by two- to threefold over a 4-year period [10]. In addition to low dietary fiber, alterations in colonic intraluminal pressures have been shown in patients with diverticular disease. Although resting intraluminal pressures between diverticular disease patients and controls do not differ significantly, higher pressures have been demonstrated in segments of colon with diverticula [11]. In addition, later studies indicate increased colonic motility, as assessed by the number and amplitude of bowel wall contractions, in the sigmoid colon of patients with diverticular disease [12-14]. Therefore, both a low-fiber diet and colonic dysmotility have been implicated in the pathogenesis of diverticular disease.

\section{Treatment options}

These are based upon the stage of disease. Table 1 depicts a scoring system that subdivides diverticulitis based upon the extent of disease identified on computerized tomography $(\mathrm{CT})$ scanning. The traditional Hinchey classification was developed before routine CT scanning [15] and we have modified it slightly to reflect contemporary management decisions that are based on CT scan findings. Most clinicians are comfortable treating patients stage IA and IB diverticulitis with intravenous (IV) antibiotics and

\section{Table 1 Perforated sigmoid diverticulitis score}

\begin{tabular}{ll}
\hline Stage & CT scan findings \\
\hline IA & Phelogmon with no abscess \\
IB & Phlegmon with abscess $\leq 4 \mathrm{~cm}$ \\
II & Phlegmon with abscess $>4 \mathrm{~cm}$ \\
III & Purulent pertonitis (no hole in colon) \\
IV & Feculent pertonitis (persistent hole in colon) \\
\hline
\end{tabular}

bowel rest. They will also readily opt for interventional radiology percutaneous drainage $(P C D)$ in patients with stage IIB disease as long as the patients do not have severe sepsis/septic shock (SS/SS). However, there is considerable controversy over what is the best option for patients who present with stage III and IV diverticulitis who have signs of SS/SS. The treatment options for these patients are described below:

\section{Three stage procedure}

While diverticulosis was initially regarded as a pathologic curiosity, the first colon resection for perforated diverticulitis was reported by Mayo in 1907 [16]. However, a subsequent report from the Mayo clinic in 1924, concluded that acute resection accentuated the infection resulting in a prohibited high mortality [17]. They recommended a colostomy with distal irrigation and then delayed resection when the patient condition improved. Over the next 20 years, a variety of procedures were performed for perforated diverticulitis. In 1942 the Massachusetts General Hospital reported their experience with these different procedures and concluded that the best outcomes were achieved with proximal diverting colostomy and then resection of the diseased colon in three to six months after the inflammation had resolved [18]. Thereafter the three stage procedure became the standard of care: $1^{\text {st }}$ - diverting transverse colostomy and drainage; $2^{\text {nd }}$ - definitive resection and colostomy after three to six months and $3^{\text {rd }}$ colostomy closure after three to six months.

\section{Two stage procedure}

After the introduction of perioperative antibiotics and improved perioperative care, case series emerged starting in the late 1950 s that demonstrated that in select circumstances the diseased colon could be safely resected at the $1^{\text {st }}$ operation. The two stage procedure: $1^{\text {st }}$ - segmental sigmoid resection with end colostomy [i.e. the Hartmann's procedure $(H P)$ originally described Henri Hartmann in 1921 for treatment of colorectal cancer] [19] and $2^{\text {nd }}$ colostomy closure after three to six months was increasingly practiced and became standard of care by the 1980s. This approach was supported by a study published in 1984 which combined patient data from 36 case series published since the late 1950s [20]. The study include a total of 821 cases of diverticulitis with purulent (i.e. stage III disease) or feculent (i.e. stage IV disease) peritonitis of which 316 patients underwent a $H P$ (with a mortality of $12 \%)$ compared to the 505 patients who underwent diverting colostomy with no resection (with a mortality of $29 \%$ ). While these retrospective case series suffer from selection bias in that the less healthy patients were more likely to undergo a diverting colostomy with no resection, this report established that a substantial portion of patients can undergo an emergency $H P$ with an acceptable mortality. 
Additionally, acute resection avoided missing a colon cancer (which occurs in up to $3 \%$ of cases) and decreased morbidity because up to $20 \%$ of the non-resected patients developed a fistula. Interestingly, there were two subsequent prospective randomized trials (PRTs) that showed divergent results. In a single center Swedish PRT, of 46 patients with stage III purulent peritonitis, 25 patients who underwent a $H P$ (with $24 \%$ mortality) compared to 21 patients who underwent colostomy with no resection (with 0\% mortality) [21]. In a multicenter French PRT of 103 patients with purulent or feculent peritonitis, 55 patients underwent a $H P$ and had a $<2 \%$ rate of post-operative sepsis with a mortality of $23 \%$ [22]. In contrast, 48 patients underwent diverting colostomy with no resection (with suture closure of the hole in the stage IV cases) had a $20 \%$ rate of post-operative sepsis with a similar mortality of $18 \%$. As a result of these and other data, the colorectal surgical specialists published an EBG in 2000 in which they concluded that the procedure of choice for perforated diverticulitis was a HP [23]. However, with the recognition up to half of the patients who underwent a $H P$ never had their colostomy reversed and that colostomy closure was a morbid procedure, many colorectal surgeons performed a primary anastomosis in select cases.

\section{Primary resection with anastomosis (PRA)}

A 2006 meta-analysis [that included 15 case series (13 retrospective)] indicated that mortality was significantly lower and there was a trend towards fewer surgical complications in patients who underwent PRA with or without a proximal diverting loop ileostomy compared those who underwent a $H P$ for perforated diverticulitis [24]. Again, while this review suffers from a selection bias where the less healthy patients were more likely to undergo a HP, it does document that emergency $P R A$ in select patients has a low anastomotic leak rate $(\sim 6 \%)$ and that in the sicker patients (stage $>$ II subset) $P R A$ and $H P$ had equivalent mortality (14.0 vs. $14.4 \%$ ). Additionally, it was recognized that $85 \%$ of patients with $P R A$ and proximal loop ileostomy had subsequent stomal closure [25]. As a result of these data, the colorectal surgical specialists updated their EBG in 2006 and recommended emergent definitive sigmoid resection for perforated diverticulitis with peritonitis but concluded that an acceptable alternative to the $H P$ (i.e. colostomy) is primary anastomosis [26]. The precise role of proximal ileostomy diversion after $P R A$ remains unsettled.

\section{Laparoscopic lavage and drainage (LLD)}

Interestingly, as the colorectal surgical specialists progressively endorsed a more aggressive approach, starting in 1996, there have been 18 case series involving 806 patients that document surprisingly better outcomes with simple LLD [27,28]. In 2008 Myers et al. reported the largest series to date with compelling results (Figure 1) [29]. Out of 1257 patients admitted for diverticulitis over seven years, 100 (7\%) had peritonitis with evidence of free air on $\mathrm{x}$-ray or CT scan. These patients were resuscitated, given a third generation cephalosporin and flagyl and then taken emergently to the OR for laparoscopy. Eight were found to have stage IV disease and underwent a HP. The remaining 92 patients underwent $L L D$. Three (3\%) of these patients died (which much lower than reported for $P R A$ or $H P$ ). An additional two patients had non-resolution, one required an $H P$, and the other had further $P C D$. Overall, 88 of the $92 L L D$ patients had resolution of their symptoms. They were discharged to home and did not undergo an elective resection. Over the ensuing 36 months, there were only two recurrences. Another recent study by Liang et al. associates supports $L L D$ [30]. They reviewed 88 cases of diverticulitis (predominantly stage III) treated laparoscopically of which 47 were treated by $L L D$ and 41 by laparoscopic $H P$ (see Table 2) [30]. Again $L L D$ appeared effective for source control and had better outcome than a laparoscopic $H P$. Interesting, they treated 5 cases of stage IV disease with $L L D$ combined with laparoscopic closure of the sigmoid colon perforation. Most recently the Dutch have reviewed their experience with $L L D$ in 38 patients and reported notably less impressive outcomes [28]. In 31 patients the $L L D$ controlled the sepsis. These patients had low mortality (1 died), acceptable morbidity and relatively rapid recovers. However, in the remaining 7 patients $L L D$ did not control abdominal sepsis, two died of multiple organ failure (MOF) and 5 required further surgical interventions ( $3 H P s, 1$ diverting stoma and 1 perforation closure). One of these died from aspiration and the remaining four experienced prolonged complicated recoveries. These authors concluded that patient selection is of utmost importance. They believe it is contraindicated in stage IV disease. Additionally they noted that patients with stage III disease who have multiple co-morbidities, immunosuppression, a high $\mathrm{C}$ reactive protein level and/or a high Mannheim Peritonitis Index are at high risk of failure and concluded that a HP as a first step is the best option in these patients.

\section{Nonoperative management (NOM)}

More recently, Costi et al. added more controversy to management options when they reported their experience with NOM of 39 hemodynamically stable patients with stage III diverticulitis [31]. Three $(8 \%)$ required an emergency operation because of clinical deterioration and underwent an HP. Seven (18\%) required later CT-guided $P C D$ of abscesses, while amazingly 29 (74\%) required no early operative intervention and hospital mortality was zero. Half of the discharged patients underwent a delayed elective sigmoid resection and of the remaining half, five had recurrent diverticulitis successfully treated medically 


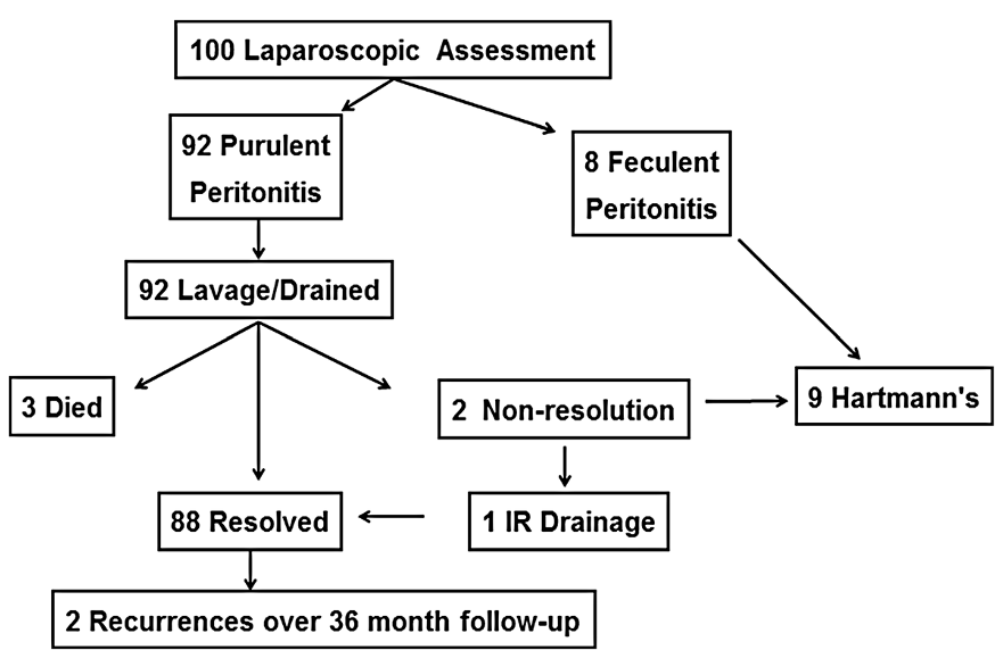

Figure 1 Experience with laporoscopic lavage and drainage.

(with later elective resection). Of note, patients who underwent delayed elective resection experienced higher than expected morbidity leading the authors to conclude that perhaps delayed resection is not necessary and causes more harm than good. It is surmised with resolution of an acute perforation; local fibrosis prevents the recurrent perforation of the diverticulum. Dr Costi has cautioned that it is imperative to differentiate stage III from stage IV disease. They accomplish this by using a CT scan protocol that utilizes rectal contrast and if the any extravasation is seen, the patient is not a candidate for NOM.

\section{Staged laparotomy}

The concept of a planned relaparotomy for fulminant peritonitis has been debated for over thirty years. Reoperations are performed every 48 hours for "washouts" until the abdomen is free of ongoing peritonitis and then the abdomen is closed. This supposedly prevents and/or provides early treatment for secondary infections thus decreasing late MOF and deaths. The downside of the planned relaparotomy approach is increased resource

Table 2 Laparoscopic lavage and drainage (LLD) compared to laparoscopic hatman's procedure (LHP)

\begin{tabular}{llll}
\hline & LLD & LHP & p value \\
\hline \# of patient & 47 & 41 & \\
OR time (minutes) & $100 \pm 40$ & $182 \pm 55$ & 0.001 \\
Conversion & $2 \%$ & $15 \%$ & 0.05 \\
Complications & $4 \%$ & $13 \%$ & 0.05 \\
Mortality & $0 \%$ & $2.4 \%$ & ns \\
Hospital stay (days) & $6.6 \pm 2.4$ & $16.6 \pm 10$ & 0.01 \\
Colostomy closure & na & $72 \%$ & na \\
Elective resection & $45 \%$ & na & na \\
\hline
\end{tabular}

utilization and the increased potential risk for gastrointestinal fistulas and delayed hernias. The alternative is referred to as relaparotomy on-demand where relaparotomy is performed for clinical deterioration or lack of improvement. The potential downside to this approach is harmful delays in diagnosing secondary abdominal infections and the presence of more dense adhesions if there is a need to re-operate. Over the years there have been eight case series that have offered conflicting results regarding the impact of these strategies on outcome. A meta-analysis of these data concluded relaparotomy ondemand was the preferred approach in patients with APACHE II $<10$ [32]. Furthermore, a recent PRT by van Ruler et. al. in patients with APACHE II > 10 indicates that the practice of planned relaparotomy offered no clinical advantage over relaparotomy on-demand and was associated with substantial increases in expenditure of hospital resources [33].

\section{Damage control laparotomy (DCL)}

In the early 1980's trauma surgeons recognized when they operated in the setting of the "bloody viscous cycle" of acidosis, hypothermia and coagulopathy, operating room (OR) mortality from bleeding was unacceptably high [34]. This prompted the develop of the concept of an abbreviated laparotomy using gauze packing to stop bleeding combined temporary abdominal closure $(T A C)$ and triage to the ICU with the intent of optimizing physiology [35]. The patient is taken back to the OR after 24-48 hours for definitive treatment of injuries and abdominal closure. This concept was initially promoted for major liver injuries as a way to avoid major liver resections but was soon extended to all emergency trauma laparotomies [36]. Over the next decade this concept evolved into "damage control" which was a major paradigm shift for trauma 
surgeons [37-39]. This practice became standard of care worldwide by the mid-1990s and has saved the lives of many patients who previously exsanguinated on the OR table. However, the role of $D C L$ in emergency general surgery is controversial [40-43]. It is often confused with the concept of a planned relaparotomy (described above). Moore et al. proposed that the purpose of $D C L$ in intraabdominal sepsis is different from trauma. While the "bloody viscous cycle" can occur with intra-abdominal sepsis, exsanguination is uncommon short of technical mishaps. Rather patients with intra-abdominal sepsis can present in persistent septic shock [40]. Initially, they are too unstable to undergo immediate operation. An immediate operation in these patients results in a high risk for postoperative acute kidney injury (AKI) sets the stage for MOF, prolonged intensive care unit (ICU) stays and dismal long-term outcomes $[40,44,45]$. By their protocol, patient presenting in septic shock warrant pre-operative optimization with early goal directed therapy. If they are not optimized pre-operatively, they will experience profound hypotension when subjected to general anesthesia and require high doses vasopressors (typically boluses of phenylephrine) to maintain mean arterial pressure (MAP) and if they undergo a traditional $H P$ this will be prolonged and contribute substantially to post-operative AKI [45]. After optimization (described below), the patient is taken to the OR. After undergoing general anesthesia, the surgeon assesses whether the patient is still in septic shock. If so, the OR team is informed that a $D C L$ is going to be performed. They should anticipate a short operation (roughly 30-45 minutes) and get the supplies necessary for a TAC. A limited colon resection of the inflamed perforated colon is performed using staplers (referred to as a "perforection") with no colostomy and a TAC is performed using a "vac pack" technique. The patient is returned to the ICU for ongoing resuscitation. Once physiologic abnormalities are corrected, the patient is returned to the OR for peritoneal lavage and colostomy formation. A definitive resection should be done if feasible for patients who have undergone a limited resection at the previous $D C L$ to prevent a fistula and recurrence. However, KafkaRitsch et al. propose an alternative reason to perform $D C L$ in patients with diverticulitis is to avoid a colostomy by performing a delayed anastomosis [43]. In a prospective study 51 patients with perforated diverticulitis (stage III/ IV) were initially managed with limited resection, lavage and $T A C$ with a vacuum-assisted closure device followed by second, reconstructive operation 24-48 hours later supervised by a colorectal surgical specialist. Bowel continuity was restored in $38(84 \%)$ patients, of which four were protected by a loop ileostomy. Five anastomotic leaks (13\%) were encountered requiring loop ileostomy in two patients or $H P$ in three patients. Postoperative abscesses were seen in four patients, abdominal wall dehiscence in one and relaparotomy for drain-related small bowel perforation in one. The overall mortality rate was $10 \%$ and $35 / 46$ (76\%) of the surviving patients left the hospital with reconstructed colon continuity. Fascial closure was achieved in all patients.

\section{Summary}

Over the last century, based primarily on retrospective case series, we have seen a progression in the treatment of perforated diverticulitis from a conservative 3 stage procedure in the 1940s to the 2 stage HP in the 1980s (which is practiced by many surgeons today) and most recently an aggressive one stage PRA that is being promoted by colorectal surgical specialists. However, now there is emerging evidence that we should adopt a minimalist strategy of $L L D$ or $N O M$ in the less sick patients while employing $D C L$ in the sickest patients. Unfortunately, like most of the literature on diverticulitis, these recent studies are retrospective and we are awaiting the results of PRTs that are ongoing in Europe [46,47]. Given this lack of high grade data, we propose a reasonable treatment algorithm based on the expert opinion of surgeons who actively practice emergency surgery [40,47-49].

\section{Decision making algorithm}

Key Questions that drive decision making include:

1) Is clinical diagnosis consistent with perforated sigmoid diverticulitis?

2) Does the patient require an emergency operation?

3) Is the patient in septic shock and should undergo pre-operative optimization?

4) Is the patient in septic shock and should undergo damage control laparotomy?

5) Should the patient undergo laparoscopic lavage and drainage?

6) What is a definitive resection and should the patient undergo colostomy or a primary anastomosis?

7) Should the patient undergo interventional radiologic percutaneous drainage?

8) Should the patient be observed and what constitutes observational therapy?

9) Should patients undergo delayed colonoscopy after acute diverticulitis to rule out colon cancer?

10)Should patients with perforated sigmoid diverticulitis who respond to conservative therapy undergo delayed elective colon resection?

11)Should patients after a Hartmann's Procedure have a colostomy closure and what is the optimal time?

Figure 2 depicts our proposed management algorithm for acute complicated diverticulitis. 


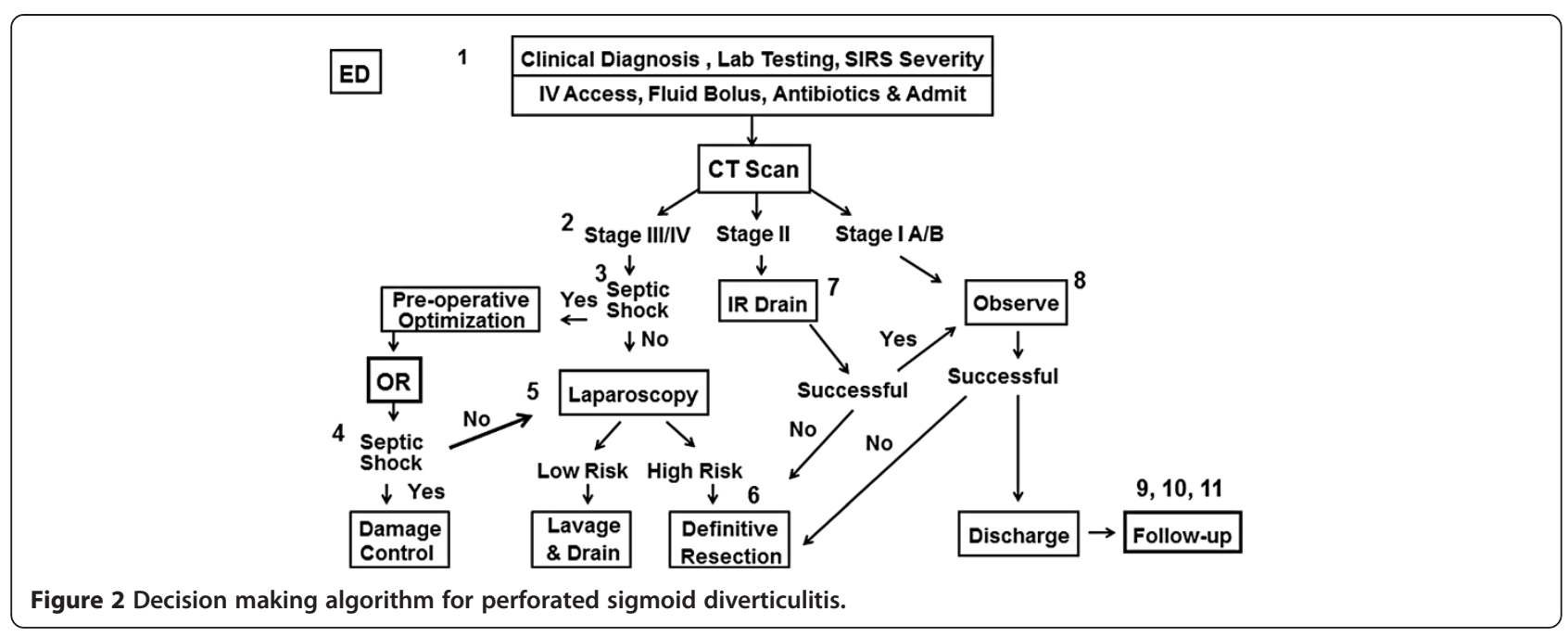

\section{Making the clinical diagnosis}

When encountering a new patient in the emergency department (ED), the surgeon first makes the clinical diagnosis of diverticulitis based on history, physical exam and routine laboratory testing. Abdominal pain is the primary presenting symptom. It is typically located in the left lower quadrant; however, a redundant sigmoid colon can reach the right lower quadrant and mimic appendicitis. Localized peritoneal irritation can result in guarding and rebound tenderness. Free perforation often presents as frank peritonitis. Fever and leukocytosis are usually present and assist in making the clinical diagnosis. Nausea and vomiting are the most notable symptoms when a stricture results in an obstruction. The initial assessment should include a) an assessment of the severity of the signs of the systemic inflammatory response syndrome (SIRS) including heart rate, respiratory rate, temperature and white blood cell count, b) peritonitis on physical exam and c) signs of organ dysfunctions. Patients with clinical diagnosis consistent with diverticulitis who have concerning signs of sepsis should be considered to be at high risk for complicated diverticulitis. They should have IV access obtained, be given a bolus of IV isotonic crystalloids $(20 \mathrm{ml} / \mathrm{kg}$ ), be administered IV antibiotics, and be admitted to the hospital.

These patients should undergo CT scanning with IV contrast of the abdomen and pelvis with the exception of pregnant women where ultrasound is recommended [50]. CT scanning has a high sensitivity and specificity in confirming the diagnosis and identifying patients who are candidates for therapeutic PCD [51,52]. CT scanning also excludes other causes of left lower quadrant abdominal pain (e.g. leaking abdominal aortic aneurism or an ovarian abscess), but is not reliable in differentiating acute diverticulitis from colon malignancy [53].

\section{Patients who require an emergency operation}

This decision mostly pertains to patients with stage III and stage IV diverticulitis who present with signs of sepsis and need an emergency operation for source control. The timing and type of source control is unclear. Traditionally, all of these patients were taken expediently to the OR. However, there has been a shift in this paradigm with the recognition that operating in the setting of septic shock sets the stage for postoperative AKI, MOF, prolonged ICU stays and dismal long-term outcomes $[40,44,45]$. Specifically, we believe patients in septic shock benefit from pre-operative optimization. This takes $2-3$ hours $[54,55]$. It starts with obtaining two large bore IV lines through which broad spectrum antibiotics and a bolus of isotonic crystalloids $(20 \mathrm{ml} / \mathrm{kg})$ are administered. A central line (via the internal jugular vein placed under ultrasound guidance) and an arterial line are concurrently placed. With ongoing volume loading, CVP is increased to above 10 $\mathrm{cmH}_{2} \mathrm{O}$. At this point the patient is intubated and ventilation optimized. Norepinephrine is titrated to maintain MAP $>65 \mathrm{~mm} \mathrm{Hg}$ and if high doses are required, stress dose steroids and low dose vasopressin are administered. Electrolyte abnormalities are corrected and blood products are administered based on institutional guidelines. Lactate and mixed venous hemoglobin saturations are measured and trended to assess the adequacy of the resuscitative efforts. Once the patient is stable enough to tolerate OR transport and general anesthesia, he/she should be transported to the OR for a source control operation. After the patient is in the OR and under general anesthesia, the surgeon needs to reassess whether the patient is still in septic shock. If so, the OR team should be informed that a $D C L$ is going to be performed (described above). They should anticipate a short operation (roughly 30-45 minutes) and get the supplies necessary for a TAC. 
While the role of $D C L$ in this setting is controversial, it should not be confused with the concept of a planned relaparotomy (described above) [32]. At the second operation, we believe that the decision to perform a delayed anastomosis should be individualized based on the current physiology, the condition of bowel, patient co-morbidities, and surgeon experience. However, in most patients who have undergone $D C L$ because of persistent septic shock, bowel wall edema and persistent hypoperfusion make a delayed anastomosis an unsafe option.

For patients who have stage III and stage IV disease and concerning signs of sepsis but are not in septic shock also need source control. While traditionally these patients were taken expeditiously to the OR for a $H P$ or a $P R A$, we believe that the recent case series indicate that $L L D$ is a viable option that should be employed to low risk patients but recommend a definitive sigmoid resection for high risk that include patients who are a) immunocompromised, b) have severe co-morbidities c) organ dysfunctions attributable to ongoing sepsis or d) stage IV disease. The again the decision to perform an anastomosis should be individualized based on the current physiology, the condition of bowel, patient co-morbidities, and surgeon experience.

\section{Patients who do not require an emergency operation}

Initial recommended treatment of stage IA and IB diverticulitis includes a) nil per os (NPO), b) nasogastric tube to treat (if present) symptoms of nausea, vomiting and abdominal distention and c) antibiotics with activity against common gram-negative and anaerobic pathogens. A number of single agents and combination regimens provide such activity. However, there is little evidence on which to base selection of specific antimicrobial regimens, and no regimen has demonstrated superiority [56,57]. In general, episodes of diverticulitis severe enough to warrant hospitalization should be initially managed with IV antibiotics. Oral antibiotic therapy can be started when the patient's condition improves and continued as outpatient treatment. There is a paucity of data regarding the optimal duration of antimicrobial therapy.

Patients with stage II diverticulitis should be managed as above but should also be evaluated by interventional radiology for CT guided PCD [51]. The preferred approach is trans-abdominal either anterior or lateral, attempting to avoid the inferior epigastric or deep circumflex iliac vessels. Other approaches include transgluteal, transperineal, transvaginal or transanal. Reported failure rates for PCD range from $15 \%$ to $30 \%$ with a complication rate of $5 \%$ (including bleeding, perforation of a hollow viscous or fistula formation) [58-60].

\section{Observation}

Patients with stage IA, IB and II diverticulitis should be treated as described above and observed with serial a) physical exams, b) assessments of SIRS severity and c) laboratory evidence organ dysfunctions. It is expected that their clinical condition will improve over 72 hours. If it does not improve or their condition worsens they should undergo an urgent operation. Patients who resolve their symptoms should be discharged to home on oral antibiotics with follow-up (described below).

\section{Patients who fail observation}

These patients should undergo definitive sigmoid resection. While laparoscopic colon resection compared to open laparotomy colon resection is associated with better outcomes in elective surgery $[61,62]$, there is no evidence that the same is true in urgent/emergent operations. Definitive sigmoid resection requires mobilization of the sigmoid colon with avoidance of injury to the ureters. Ureteral stents should be used selectively in those patients with abscesses or excessive inflammation in the pelvis. For definitive resection the distal margin of resection should be the upper rectum [63] while the proximal margin of resection should go back to non-inflamed descending colon. All diverticuli do not need to be resected. The splenic flexure is generally not mobilized unless needed to form colostomy when indicated. As previously discussed, the major debate is whether to perform a $P R A$ or a $H P$. A variety of factors need to be considered including a) disease severity b) condition of bowel at the site of anastomosis, c) patient physiology, d) nutritional status, e) patient co-morbidities, f) hospital/situational factors and g) surgeon experience. Another unresolved debate is should a protecting diverting ileostomy be added if a PRA is performed? Unless conditions are optimal, this is the prudent option. The use of perioperative colonic lavage appears to lower complications with $P R A$, but the supporting evidence is limited [64]. Omentoplasty does not offer any benefits [65]. The inferior mesenteric artery should be preserved when feasible to lower the risk of an anastomotic leak [66].

\section{Discharge and follow-up}

Although there is lack of evidence that lifestyle changes will help prevent recurrent diverticulitis, it is likely that measures thought to prevent an initial episode of diverticulitis would also apply to preventing a recurrence. These healthy lifestyles should be recommended upon discharge and include a) physical exercise, b) a high fiber diet, c) reduced red meat, d) minimize alcohol consumption and e) stop smoking $[67,68]$. Patients should return to the clinic if symptoms recur and have a follow-up clinic appointment at four to six weeks to address three issues.

\section{Colonoscopy}

After the inflammation from a new onset of diverticulitis has resolved, traditionally patients have undergone colonoscopy to rule out colon cancer. However, the need for 
routine colonoscopy has recently been questioned [69]. Colonoscopy is a time-consuming and a resource burden on an already-stretched health care system. In addition, endoscopy may be technically more difficult in these patients with an risk iatrogenic bowel perforation $(\sim 0.1 \%)$. The reported incidence of colon cancer in CT diagnosed acute diverticulitis ranges from 0.5 to $3 \%$. But with technological improvement in quality and resolution of CT has led to better evaluation of the colon in the affected segment and the chances of missing a colon cancer has decreased. A recent study by Sallinen et al. provides additional insight into this debate [70]. They looked 536 patients were admitted to the hospital for diverticulitis who were treated without an operation. Of these patients 394 underwent a delayed colonoscopy and $17(2.7 \%)$ were found to have cancer. Sixteen cancer cases (94\%) had abscess in the CT, whereas the remaining case had pericolic extraluminal air, but no abscess. Of the patients with abscess, $11 \%$ had cancer mimicking acute diverticulitis. No cancer was found in patients with uncomplicated diverticulitis. Besides abscess, other independent risk factors for cancer included suspicion of cancer by a radiologist, thickness of bowel wall over $15 \mathrm{~mm}$, no diverticula seen, and previously undiagnosed metastases. They conclude that routine colonoscopy after CT-proven uncomplicated diverticulitis seems unnecessary. However, colonoscopy should be performed in patients diagnosed with a diverticular abscess or those with one of the independent risk factors. Barium enema or CT colonography can be used in cases where a complete colonoscopy cannot be accomplished.

\section{Prophylactic sigmoid colectomy}

In the recent past, a delayed elective sigmoid resection was recommended after two cases of uncomplicated or one case of complicated acute diverticulitis [23]. The idea was that the elective resection would be less morbid than a recurrent bout of diverticulitis. However, an elective resection has risks including a) up to $10 \%$ recurrence, b) $1-2 \%$ mortality and c) a $10 \%$ need for a stoma. Additionally, it is now apparent that the majority of patients with severe diverticulitis present at their $1^{\text {st }}$ episode and that recurrent diverticulitis is relatively rare (roughly $2 \%$ per year). Additionally, when it recurs it is less likely to require an operation and has a very low mortality. As a result the indications for elective resection after acute diverticulitis have changed substantially [67,68,71-74]. The following is a recommended list:

a) a Elective resection should be done after one documented episode acute diverticulitis in patients with one or more of the following risk factors including immunosuppression, chronic use of steroids, chronic renal failure, diabetes mellitus, COPD, or collagen vascular disease. b) For patients without the above risk factors, the preferred timing of elective surgery is after the $3^{\text {rd }}$ or $4^{\text {th }}$ episode of uncomplicated diverticulitis.

c) Patients with one episode of complicated diverticulitis with persistent or recurrent symptoms.

d) Patients with complicated diverticulitis who have an anatomic deformity including a stricture or fistula.

The timing of this elective colectomy is debated but generally one waits $4-6$ weeks to allow the inflammation to subside $[75,76]$. Laparoscopic colectomy is preferred open colectomy $[61,62]$.

\section{Colostomy closure}

For patients who have undergone a $H P$, colostomy closure is performed in only about half of the patients [25,77]. Many of the patients are elderly with multiple risk factors that contraindicate a second surgical procedure. Additionally, colostomy closure carries significant risk of perioperative complications (10 to 40\%) [78]. Patients who are satisfied with living with a colostomy may not want assume these risks as well as the time and the expense of a second operation. The optimal timing colostomy closure it not clear $[79,80]$. It should not be performed until the patient has resolved their acute phase response and resolved nutritional deficiencies to optimize wound healing reducing the risk of anastomotic leak and wound infection. This usually takes three to six months but sometimes up to a year or never. It depends of the patient's age, comorbidities and how deconditioned they were at the time of hospital discharge. Recent studies have documented that the long-term outcomes of elderly patients after being hospitalized for sepsis is notably poor $[81,82]$.

\section{Conclusion}

Based on available clinical data and our collective expert opinions, we propose a management strategy that we feel is rational and safe. All patients with presumed complicated diverticulitis should undergo CT scanning with IV contrast. This will confirm the clinical diagnosis and allow staging of the disease. Therapeutic decision in the based on a) stage of disease, b) patient co-morbidity and c) sepsis severity. Patients with stage I/II disease generally do not present with severe sepsis/septic shock (SS/SS) and can be safely treated with bowel rest, IV antibiotics and $P D C$ of larger abscesses. If stage I/II the fail $N O M$ or progress into SS/SS they should undergo PRA or HP depending a variety factors outlined above. Patients with stage III/IV disease may present in septic shock. If so they should undergo pre-operative optimization and if septic shock persists once in the operating room (OR), they should undergo $D C L$ with a limited resection. If conditions are optimal at $2^{\text {nd }}$ OR a delayed $P R A$ should be performed. If condition are unfavorable, and $H P$ should be done. If 
patients stage III/IV do not present in septic shock they should be taken to the OR and undergo laparoscopy. Low risk patients should undergo $L L D$ while high risk patients [i.e. a) immunocompromised, b) have severe co-morbidities c) organ dysfunctions attributable to ongoing sepsis or d) stage IV disease] should undergo $P R A$ or $H P$ depending a variety factors outlined above. Proximal diverting ileostomy should be used liberally with $P R A$.

\section{Abbreviations}

CT: Computerized tomographic; CVP: Central venous pressure; ED: Emergency room; EBG: Evidence based guideline; DCL: Damage control laparotomy; HP: Hartmann's procedure; IV: Intravenous; LLD: Laparoscopic lavage and drainage; MAP: Mean arterial pressure; MOF: Multiple organ failure; NOM: Nonoperative management; OR: Operating room; PCD: Percutaneous drainage; PRA: Primary resection anastomosis; PRTs: Prospective randomized trials; SS/SS: Severe sepsis/septic shock; TAC: Temporary abdominal closure.

\section{Competing interests}

The authors have no competing interests and nothing to disclose.

\section{Authors' contributions}

All of the authors (FM FC,EM, AL, and AP) have a) made substantial contributions to conception and design of this position paper, b) been involved in acquisition of relevant references and their interpretation; c) been involved in drafting the manuscript or revising it critically for important intellectual content; d) given final approval of the version to be published; and e) agree to be accountable for all aspects of the work in ensuring that questions related to the accuracy or integrity of any part of the work are appropriately investigated and resolved. All authors read and approved the final manuscript.

\section{Author details}

'Acute Care Surgery, University of Florida, 1600 Southwest Archer Road, PO Box 100108, Gainesville, FL 32610-0108, USA. ${ }^{2}$ Emergency Surgery Department, Parma University Hospital, Via Cracvia 23, Bologna 40139, Italy. ${ }^{3}$ University of Colorado Health Science Center, Denver Health Science Center, 777 Bannock Street, Denver, CO 80204-4507, USA. ${ }^{4}$ Department of Abdominal Surgery, University of Helsinki, Haartmaninkatu 4, PO Box 340, Meilahi Hospital, FIN-00029 HUS, Helsinki, HUS 00290, Finland. ${ }^{5}$ University of Pittsburgh, F-1281, UPMC-Presbyterian, Pittsburgh, PA 15213, USA.

Received: 25 November 2013 Accepted: 26 November 2013 Published: 26 December 2013

\section{References}

1. Shafi S, Aboutanos MB, Agarwal S Jr, Brown CV, Crandall M, Feliciano DV, Guillamondegui O, Haider A, Inaba K, Osler TM, Ross S, Rozycki GS, Tominaga GT, Assessment ACS, Patient O: Emergency general surgery: definition and estimated burden of disease. I Trauma Acute Care Surg 2013, 74(4):1092-1097. doi:10.1097/TA.0b013e31827e1bc7. PubMed PMID: 23511150.

2. Moore FA, Moore EE, Burlew CC, Coimbra R, Mclntyre RC Jr, Davis JW, Sperry J, Biffl WL: Western Trauma Association critical decisions in trauma: management of complicated diverticulitis. J Trauma Acute Care Surg 2012, 73(6):1365-1371. doi:10.1097/TA.0b013e31827826d8. PubMed PMID: 23188229

3. Etzioni DA, Mack TM, Beart RW Jr, Kaiser AM: Diverticulitis in the United States: 1998-2005: changing patterns of disease and treatment. Ann Surg 2009, 249(2):210-217. doi:10.1097/SLA.0b013e3181952888. PubMed PMID: 19212172.

4. Sethbhakdi S: Pathogenesis of colonic diverticulitis and diverticulosis. Postarad Med 1976, 60(6):76-81. PubMed PMID: 792842.

5. Morris CR, Harvey IM, Stebbings WS, Hart AR: Incidence of perforated diverticulitis and risk factors for death in a UK population. Br J Surg 2008, 95(7):876-881. doi:10.1002/bjs.6226. PubMed PMID: 18509877.
6. Hart AR, Kennedy HJ, Stebbings WS, Day NE: How frequently do large bowel diverticula perforate? An incidence and cross-sectional study. Eur J Gastroenterol Hepatol 2000, 12(6):661-665. PubMed PMID: 10912487.

7. Painter NS, Burkitt DP: Diverticular disease of the colon, a 20th century problem. Clin Gastroenterol 1975, 4(1):3-21. PubMed PMID: 1109818.

8. Painter NS: Diverticular disease of the colon. The first of the Western diseases shown to be due to a deficiency of dietary fibre. South Afr Med J =SuidAfrikaanse Tydskrif Vir Geneeskunde 1982, 61(26):1016-1020.

9. Unlu C, Daniels L, Vrouenraets BC, Boermeester MA: A systematic review of high-fibre dietary therapy in diverticular disease. Int $J$ Colorectal Dis 2012, 27(4):419-427. doi:10.1007/s00384-011-1308-3. PubMed PMID: 21922199; PubMed Central PMCID: PMC3308000.

10. Aldoori WH, Giovannucci EL, Rimm EB, Wing AL, Trichopoulos DV, Willett WC: A prospective study of diet and the risk of symptomatic diverticular disease in men. Am J Clin Nutr 1994, 60(5):757-764. PubMed PMID: 7942584.

11. Painter NS, Truelove SC, Ardran GM, Tuckey M: Segmentation and the localization of intraluminal pressures in the human colon, with special reference to the pathogenesis of colonic diverticula. Gastroenterology 1965, 49:169-177. PubMed PMID: 14323727.

12. Commane DM, Arasaradnam RP, Mills S, Mathers JC, Bradburn M: Diet, ageing and genetic factors in the pathogenesis of diverticular disease. World J Gastroenterol: WJG 2009, 15(20):2479-2488. PubMed PMID: 19468998; PubMed Central PMCID: PMC2686906.

13. Trotman IF, Misiewicz Jj: Sigmoid motility in diverticular disease and the irritable bowel syndrome. Gut 1988, 29(2):218-222. PubMed PMID: 3345933; PubMed Central PMCID: PMC1433293.

14. Bassotti G, Battaglia E, Spinozzi F, Pelli MA, Tonini M: Twenty-four hour recordings of colonic motility in patients with diverticular disease: evidence for abnormal motility and propulsive activity. Dis Colon Rectum 2001, 44(12):1814-1820. PubMed PMID: 11742167.

15. Hinchey EJ, Schaal PG, Richards GK: Treatment of perforated diverticular disease of the colon. Adv Surg 1978, 12:85-109. PubMed PMID: 735943.

16. Mayo WJWLB, Griffin $\mathrm{HZ}$ : Acquired diverticulitis of the large intestine. Surg Gynec Obst 1907, 5:8-15. Epub.

17. Judd ES, Pollock LW: Diverticulitis of the Colon. Ann Surg 1924, 80(3):425-438. PubMed PMID: 17865098; PubMed Central PMCID: PMC1399746.

18. Smithwick RH: Experiences with the surgical management of diverticulitis of the sigmoid. Ann Surg 1942, 115(6):969-985. PubMed PMID: 17858058; PubMed Central PMCID: PMC1543865.

19. Hartmann H: Nouveau procede d'ablation des cancers de la partie terminale du colon pelvien. Trentieme Congres de Chirurgie 1921, 28:411.

20. Krukowski ZH, Matheson NA: Emergency surgery for diverticular disease complicated by generalized and faecal peritonitis: a review. $\mathrm{Br} / \mathrm{Surg}$ 1984, 71(12):921-927. PubMed PMID: 6388723.

21. Kronborg O: Treatment of perforated sigmoid diverticulitis: a prospective randomized trial. Br J Surg 1993, 80(4):505-507. PubMed PMID: 8495323.

22. Zeitoun G, Laurent A, Rouffet F, Hay J, Fingerhut A, Paquet J, Peillon C, Research TF: Multicentre, randomized clinical trial of primary versus secondary sigmoid resection in generalized peritonitis complicating sigmoid diverticulitis. Br J Surg 2000, 87(10):1366-1374. doi:10.1046/.1365-2168.2000.01552.x. PubMed PMID: 11044163.

23. Wong WD, Wexner SD, Lowry A, Vernava A 3rd, Burnstein M, Denstman F, Fazio V, Kerner B, Moore R, Oliver G, Peters W, Ross T, Senatore P, Simmang C: Practice parameters for the treatment of sigmoid diverticulitissupporting documentation. The Standards Task Force. The American Society of Colon and Rectal Surgeons. Dis Colon Rectum 2000, 43(3):290-297. PubMed PMID: 10733108

24. Constantinides VA, Tekkis PP, Athanasiou T, Aziz O, Purkayastha S, Remzi FH, Fazio WW, Aydin N, Darzi A, Senapati A: Primary resection with anastomosis vs. Hartmann's procedure in nonelective surgery for acute colonic diverticulitis: a systematic review. Dis Colon Rectum 2006, 49(7):966-981. doi:10.1007/s10350-006-0547-9. PubMed PMID: 16752192

25. Alizai PH, Schulze-Hagen M, Klink CD, Ulmer F, Roeth AA, Neumann UP, Jansen M, Rosch R: Primary anastomosis with a defunctioning stoma versus Hartmann's procedure for perforated diverticulitis-a comparison of stoma reversal rates. Int J Colorectal Dis 2013, 28(12):1681-1688. doi:10.1007/s00384-013-1753-2. PubMed PMID: 23913315.

26. Rafferty J, Shellito P, Hyman NH, Buie WD, Standards Committee of American Society of C, Rectal S: Practice parameters for sigmoid diverticulitis. Dis Colon Rectum 2006, 49(7):939-944. doi:10.1007/s10350-006-0578-2. PubMed PMID: 16741596. 
27. Rogers AC, Collins D, O'Sullivan GC, Winter DC: Laparoscopic lavage for perforated diverticulitis: a population analysis. Dis Colon Rectum 2012, 55(9):932-938. doi:10.1097/DCR.0b013e31826178d0. PubMed PMID: 22874599.

28. Swank HA, Mulder IM, Hoofwijk AG, Nienhuijs SW, Lange JF, Bemelman WA, Dutch Diverticular Disease Collaborative Study G: Early experience with laparoscopic lavage for perforated diverticulitis. Br J Surg 2013, 100(5):704-710. doi:10.1002/bjs.9063. PubMed PMID: 23404411.

29. Myers E, Hurley M, O'Sullivan GC, Kavanagh D, Wilson I, Winter DC: Laparoscopic peritoneal lavage for generalized peritonitis due to perforated diverticulitis. Br J Surg 2008, 95(1):97-101. doi:10.1002/bjs.6024. PubMed PMID: 18076019

30. Liang S, Russek K, Franklin ME Jr: Damage control strategy for the management of perforated diverticulitis with generalized peritonitis: laparoscopic lavage and drainage vs. laparoscopic Hartmann's procedure. Surg Endosc 2012, 26(10):2835-2842. doi:10.1007/s00464-012-2255-y. PubMed PMID: 22543992

31. Costi R, Cauchy F, Le Bian A, Honart JF, Creuze N, Smadja C: Challenging a classic myth: pneumoperitoneum associated with acute diverticulitis is not an indication for open or laparoscopic emergency surgery in hemodynamically stable patients. A 10-year experience with a nonoperative treatment. Surg Endosc 2012, 26(7):2061-2071. doi:10.1007/s00464-012-2157-z. PubMed PMID: 22274929.

32. Lamme B, Boermeester MA, Reitsma JB, Mahler CW, Obertop H, Gouma DJ: Meta-analysis of relaparotomy for secondary peritonitis. Br J Surg 2002, 89(12):1516-1524. doi:10.1046/j.1365-2168.2002.02293.x. PubMed PMID: 12445059

33. van Ruler O, Mahler CW, Boer KR, Reuland EA, Gooszen HG, Opmeer BC, de Graaf PW, Lamme B, Gerhards MF, Steller EP, van Till JW, de Borgie CJ, Gouma DJ, Reitsma JB, Boermeester MA, Dutch Peritonitis Study G: Comparison of on-demand vs planned relaparotomy strategy in patients with severe peritonitis: a randomized trial. JAMA: J Am Med Assoc 2007 298(8):865-872. doi:10.1001/jama.298.8.865. PubMed PMID: 17712070.

34. Kashuk JL, Moore EE, Millikan JS, Moore JB: Major abdominal vascular trauma-a unified approach. J Trauma 1982, 22(8):672-679. PubMed PMID: 6980992.

35. Stone $H H$, Strom PR, Mullins RJ: Management of the major coagulopathy with onset during laparotomy. Ann Surg 1983, 197(5):532-535. PubMed PMID: 6847272; PubMed Central PMCID: PMC1353025.

36. Feliciano DV, Mattox KL, Burch JM, Bitondo CG, Jordan GL Jr: Packing for control of hepatic hemorrhage. J Trauma 1986, 26(8):738-743. PubMed PMID: 3488413.

37. Burch JM, Ortiz VB, Richardson RJ, Martin RR, Mattox KL, Jordan GL Jr: Abbreviated laparotomy and planned reoperation for critically injured patients. Ann Surg 1992, 215(5):476-483. PubMed PMID: 1616384; PubMed Central PMCID: PMC1242479.

38. Morris JA Jr, Eddy VA, Blinman TA, Rutherford EJ, Sharp KW: The staged celiotomy for trauma. Issues in unpacking and reconstruction. Ann Surg 1993, 217(5):576-584. discussion 84-6. PubMed PMID: 8489321; PubMed Central PMCID: PMC1242849.

39. Rotondo MF, Schwab CW, McGonigal MD, Phillips GR 3rd, Fruchterman TM Kauder DR, Latenser BA, Angood PA: 'Damage control': an approach for improved survival in exsanguinating penetrating abdominal injury. J Trauma 1993, 35(3):375-382. discussion 82-3. PubMed PMID: 8371295.

40. Moore LJ, Turner KL, Jones SL, Fahy BN, Moore FA: Availability of acute care surgeons improves outcomes in patients requiring emergent colon surgery. Am J Surg 2011, 202(6):837-842. doi:10.1016/j.amjsurg.2011.07.006. PubMed PMID: 22014648

41. Finlay IG, Edwards TJ, Lambert AW: Damage control laparotomy. Br J Surg 2004, 91(1):83-85. doi:10.1002/bjs.4434. PubMed PMID: 14716799.

42. Stawicki SP, Brooks A, Bilski T, Scaff D, Gupta R, Schwab CW, Gracias VH: The concept of damage control: extending the paradigm to emergency general surgery. Injury 2008, 39(1):93-101. doi:10.1016/j.injury.2007.06.011. PubMed PMID: 17888435

43. Kafka-Ritsch R, Birkfellner F, Perathoner A, Raab H, Nehoda H, Pratschke J, Zitt M: Damage control surgery with abdominal vacuum and delayed bowel reconstruction in patients with perforated diverticulitis Hinchey III/IV. J Gastrointest Surg: Offic J Soc Surg Aliment Tract 2012, 16(10):1915-1922. doi:10.1007/s11605-012-1977-4. PubMed PMID: 22843083.

44. Gentile LF, Cuenca AG, Efron PA, Ang D, Bihorac A, McKinley BA, Moldawer $L L$, Moore FA: Persistent inflammation and immunosuppression: a common syndrome and new horizon for surgical intensive care.
J Trauma Acute Care Surg 2012, 72(6):1491-1501. doi:10.1097/ TA.0b013e318256e000. PubMed PMID: 22695412; PubMed Central PMCID: PMC3705923.

45. White LE, Hassoun HT, Bihorac A, Moore LJ, Sailors RM, McKinley BA, Valdivia A, Moore FA: Acute kidney injury is surprisingly common and a powerful predictor of mortality in surgical sepsis. J Trauma Acute Care Surg 2013, 75(3):432-438. doi:10.1097/TA.0b013e31829de6cd. PubMed PMID: 24089113.

46. Swank HA, Vermeulen J, Lange JF, Mulder IM, van der Hoeven JA, Stassen LP, Crolla RM, Sosef MN, Nienhuijs SW, Bosker RJ, Boom MJ, Kruyt PM, Swank DJ, Steup WH, de Graaf EJ, Weidema WF, Pierik RE, Prins HA, Stockmann HB, Tollenaar RA, van Wagensveld BA, Coene PP, Slooter GD, Consten EC, van Duijn EB, Gerhards MF, Hoofwijk AG, Karsten TM, Neijenhuis PA, Blanken-Peeters CF, et al: The ladies trial: laparoscopic peritoneal lavage or resection for purulent peritonitis and Hartmann's procedure or resection with primary anastomosis for purulent or faecal peritonitis in perforated diverticulitis (NTR2037). BMC Surg 2010, 10:29. doi:10.1186/1471-2482-10-29. PubMed PMID: 20955571; PubMed Central PMCID: PMC2974662.

47. Thornell A, Angenete E, Gonzales E, Heath J, Jess P, Lackberg Z, Ovesen H, Rosenberg J, Skullman S, Haglind E, Scandinavian Surgical Outcomes Research Group S: Treatment of acute diverticulitis laparoscopic lavage vs. resection (DILALA): study protocol for a randomised controlled trial. Trials 2011, 12:186. doi:10.1186/1745-6215-12-186. PubMed PMID: 21806795; PubMed Central PMCID: PMC3173351

48. Stocchi L: Current indications and role of surgery in the management of sigmoid diverticulitis. World J Gastroenterol: WJG 2010, 16(7):804-817. PubMed PMID: 20143459; PubMed Central PMCID: PMC2825327.

49. Hall J, Hammerich $K$, Roberts P: New paradigms in the management of diverticular disease. Curr Probl Surg 2010, 47(9):680-735. doi:10.1067/j.cpsurg.2010.04.005. PubMed PMID: 20684920

50. Radiology ACo: ACR Appropriateness Criteria. 2008. Available from: www.acr.org/ac.

51. Soumian S, Thomas S, Mohan PP, Khan N, Khan Z, Raju T: Management of Hinchey II diverticulitis. World J Gastroenterol: WJG 2008, 14(47):7163-7169. PubMed PMID: 19084929; PubMed Central PMCID: PMC2776873.

52. Lameris W, van Randen A, Bipat S, Bossuyt PM, Boermeester MA, Stoker J: Graded compression ultrasonography and computed tomography in acute colonic diverticulitis: meta-analysis of test accuracy. Eur Radio/ 2008, 18(11):2498-2511. doi:10.1007/s00330-008-1018-6. PubMed PMID: 18523784

53. Destigter KK, Keating DP: Imaging update: acute colonic diverticulitis. Clin Colon Rectal Surg 2009, 22(3):147-155. doi:10.1055/s-0029-1236158; PubMed PMID: 20676257; PubMed Central PMCID: PMC2780264.

54. Dellinger RP, Levy MM, Carlet JM, Bion J, Parker MM, Jaeschke R, Reinhart K, Angus DC, Brun-Buisson C, Beale R, Calandra T, Dhainaut JF, Gerlach $H_{\text {, }}$ Harvey M, Marini JJ, Marshall J, Ranieri M, Ramsay G, Sevransky J, Thompson BT, Townsend S, Vender JS, Zimmerman JL, Vincent JL, International Surviving Sepsis Campaign Guidelines C, American Association of Critical-Care N, American College of Chest P, American College of Emergency P, Canadian Critical Care S, European Society of Clinical M, et al: Surviving Sepsis Campaign: international guidelines for management of severe sepsis and septic shock: 2008. Crit Care Med 2008, 36(1):296-327. doi:10.1097/01.CCM.0000298158.12101.41. PubMed PMID: 18158437.

55. Moore LJ, Moore FA: Epidemiology of sepsis in surgical patients. Surg Clin North Am 2012, 92(6):1425-1443. doi:10.1016/j.suc.2012.08.009. PubMed PMID: 23153877

56. Byrnes MC, Mazuski JE: Antimicrobial therapy for acute colonic diverticulitis. Surg Infect 2009, 10(2):143-154. doi:10.1089/sur.2007.087. PubMed PMID: 19226204.

57. Sartelli M, Viale P, Catena F, Ansaloni L, Moore E, Malangoni M, Moore FA, Velmahos G, Coimbra R, Ivatury R, Peitzman A, Koike K, Leppaniemi A, Biffl W, Burlew CC, Balogh ZJ, Boffard K, Bendinelli C, Gupta S, Kluger Y, Agresta F, Di Saverio S, Wani I, Escalona A, Ordonez C, Fraga GP, Junior GA, Bala M, Cui Y, Marwah S, et al: 2013 WSES guidelines for management of intra-abdominal infections. World J Emerg Surg: WJES 2013, 8(1):3. doi:10.1186/1749-7922-8-3. PubMed PMID: 23294512; PubMed Central PMCID: PMC3545734

58. Ambrosetti $P$, Chautems R, Soravia C, Peiris-Waser N, Terrier F: Long-term outcome of mesocolic and pelvic diverticular abscesses of the left colon: a prospective study of 73 cases. Dis Colon Rectum 2005, 48(4):787-791. doi:10.1007/s10350-004-0853-z. PubMed PMID: 15747071.

59. Durmishi Y, Gervaz P, Brandt D, Bucher P, Platon A, Morel P, Poletti PA: Results from percutaneous drainage of Hinchey stage II diverticulitis 
guided by computed tomography scan. Surg Endosc 2006, 20(7):1129-1133. doi:10.1007/s00464-005-0574-y. PubMed PMID: 16755351.

60. Kumar RR, Kim JT, Haukoos JS, Macias LH, Dixon MR, Stamos MJ, Konyalian VR: Factors affecting the successful management of intra-abdominal abscesses with antibiotics and the need for percutaneous drainage. Dis Colon Rectum 2006, 49(2):183-189. doi:10.1007/s10350-005-0274-7. PubMed PMID: 16322960

61. Klarenbeek BR, Veenhof AA, Bergamaschi R, van der Peet $D L$, van den Broek WT, de Lange ES, Bemelman WA, Heres P, Lacy AM, Engel AF, Cuesta MA: Laparoscopic sigmoid resection for diverticulitis decreases major morbidity rates: a randomized control trial: short-term results of the Sigma Trial. Ann Surg 2009, 249(1):39-44. doi:10.1097/

SLA.0b013e31818e416a. PubMed PMID: 19106674.

62. Gervaz $P$, Inan I, Perneger T, Schiffer E, Morel P: A prospective, randomized, single-blind comparison of laparoscopic versus open sigmoid colectomy for diverticulitis. Ann Surg 2010, 252(1):3-8. doi:10.1097/SLA.0b013e3181dbb5a5. PubMed PMID: 20505508.

63. Benn PL, Wolff BG, Ilstrup DM: Level of anastomosis and recurrent colonic diverticulitis. Am J Surg 1986, 151(2):269-271. PubMed PMID: 3946763.

64. Kam MH, Tang CL, Chan E, Lim JF, Eu KW: Systematic review of intraoperative colonic irrigation vs. manual decompression in obstructed left-sided colorectal emergencies. Int J Colorectal Dis 2009, 24(9):1031-1037. doi:10.1007/s00384-009-0723-1. PubMed PMID: 19415306.

65. Merad F, Hay JM, Fingerhut A, Flamant Y, Molkhou JM, Laborde Y: Omentoplasty in the prevention of anastomotic leakage after colonic or rectal resection: a prospective randomized study in 712 patients. French Associations for Surgical Research. Ann Surg 1998, 227(2):179-186. PubMed PMID: 9488514; PubMed Central PMCID: PMC1191233.

66. Tocchi A, Mazzoni G, Fornasari V, Miccini M, Daddi G, Tagliacozzo S: Preservation of the inferior mesenteric artery in colorectal resection for complicated diverticular disease. Am J Surg 2001, 182(2):162-167. PubMed PMID: 11574089

67. Andeweg CS, Mulder IM, Felt-Bersma RJ, Verbon A, van der Wilt GJ, van Goor H, Lange JF, Stoker J, Boermeester MA, Bleichrodt RP: Guidelines of diagnostics and treatment of acute left-sided colonic diverticulitis. Dig Surg 2013, 30(4-5):278-292. doi:10.1159/000354035. PubMed PMID: 23969324.

68. Andersen JC, Bundgaard L, Elbrond H, Laurberg S, Walker LR, Stovring J, Danish SS: Danish national guidelines for treatment of diverticular disease. Danish Med J 2012, 59(5):C4453. PubMed PMID: 22549495.

69. Sharma PV, Eglinton T, Hider P, Frizelle F: Systematic Review and Metaanalysis of the Role of Routine Colonic Evaluation After Radiologically Confirmed Acute Diverticulitis. Ann Surg 2013. doi:10.1097/ SLA.0000000000000294. PubMed PMID: 24169174.

70. Sallinen V, Mentula P, Leppaniemi A: Risk of colon cancer after computed tomography-diagnosed acute diverticulitis: is routine colonoscopy necessary? Surg Endosc 2013. doi:10.1007/s00464-013-3257-0. PubMed PMID: 24178863

71. Collins D, Winter DC: Elective resection for diverticular disease: an evidence-based review. World J Surg 2008, 32(11):2429-2433. doi:10.1007/s00268-008-9705-7. PubMed PMID: 18712563.

72. Broderick-Villa G, Burchette RJ, Collins JC, Abbas MA, Haigh PI: Hospitalization for acute diverticulitis does not mandate routine elective colectomy. Arch Surg 2005, 140(6):576-581. discussion 81-3. doi:10.1001/archsurg.140.6.576. PubMed PMID: 15967905

73. Pittet O, Kotzampassakis N, Schmidt S, Denys A, Demartines N, Calmes JM: Recurrent left colonic diverticulitis episodes: more severe than the initial diverticulitis? World J Surg 2009, 33(3):547-552. doi:10.1007/s00268-008-9898-9. PubMed PMID: 19148697.

74. Klarenbeek BR, Samuels M, van der Wal MA, van der Peet DL, Meijerink WJ, Cuesta MA: Indications for elective sigmoid resection in diverticular disease. Ann Surg 2010, 251(4):670-674. doi:10.1097/SLA.0b013e3181d3447d. PubMed PMID: 20224374.

75. Reissfelder C, Buhr HJ, Ritz JP: What is the optimal time of surgical intervention after an acute attack of sigmoid diverticulitis: early or late elective laparoscopic resection? Dis Colon Rectum 2006, 49(12):1842-1848. doi:10.1007/s10350-006-0730-z. PubMed PMID: 17036202

76. Margolin DA: Timing of elective surgery for diverticular disease. Clin Colon Rectal Surg 2009, 22(3):169-172. doi:10.1055/s-0029-1236161. PubMed PMID: 20676260; PubMed Central PMCID: PMC2780261.
77. Constantinides VA, Tekkis PP, Senapati A, Association of Coloproctology of Great Britain I: Prospective multicentre evaluation of adverse outcomes following treatment for complicated diverticular disease. Br J Surg 2006, 93(12):1503-1513. doi:10.1002/bjs.5402. PubMed PMID: 17048279.

78. Demetriades D, Pezikis A, Melissas J, Parekh D, Pickles G: Factors influencing the morbidity of colostomy closure. Am J Surg 1988, 155(4):594-596. PubMed PMID: 3354784.

79. Khalid MS, Moeen S, Khan AW, Arshad R, Khan AF: Same admission colostomy closure: a prospective, randomised study in selected patient groups. Surg: J Roy Coll Surg Edinb Ireland 2005, 3(1):11-14. PubMed PMID: 15789787.

80. Roe AM, Prabhu S, Ali A, Brown C, Brodribb AJ: Reversal of Hartmann's procedure: timing and operative technique. Br J Surg 1991, 78(10):1167-1170. PubMed PMID: 1958975.

81. Iwashyna TJ, Ely EW, Smith DM, Langa KM: Long-term cognitive impairment and functional disability among survivors of severe sepsis. JAMA: J Am Med Assoc 2010, 304(16):1787-1794. doi:10.1001/jama.2010.1553. PubMed PMID: 20978258; PubMed Central PMCID: PMC3345288.

82. Iwashyna TJ, Cooke CR, Wunsch H, Kahn JM: Population burden of longterm survivorship after severe sepsis in older Americans. J Am Geriatr Soc 2012, 60(6):1070-1077. doi:10.1111/j.1532-5415.2012.03989.x. PubMed PMID: 22642542; PubMed Central PMCID: PMC3374893.

doi:10.1186/1749-7922-8-55

Cite this article as: Moore et al: Position paper: management of perforated sigmoid diverticulitis. World Journal of Emergency Surgery 2013 8:55.

\section{Submit your next manuscript to BioMed Central and take full advantage of:}

- Convenient online submission

- Thorough peer review

- No space constraints or color figure charges

- Immediate publication on acceptance

- Inclusion in PubMed, CAS, Scopus and Google Scholar

- Research which is freely available for redistribution 